\title{
Implementation of Independent Improved Neutral Current Controller Using Four Leg PV-VSI
}

\author{
Fida Hasan Md Rafi, Student member, IEEE, M. J. Hossain, Senior Member, IEEE Md. Shamiur Rahman, Student \\ member, IEEE, J. Lu, Senior Member, IEEE \\ Queensland Micro and Nano Technology Center, Griffith School of Engineering, \\ Griffith University, Gold coast, Australia. \\ Fida.rafi@griffithuni.edu.au, j.hossain@griffith.edu.au, mdshamiur.rahman@griffithuni.edu.au, j.lu@griffith.edu.au
}

\begin{abstract}
An independent improved neutral current controller is implemented in a three-phase (3p) four-wire (4w) low voltage (LV) distribution network with a four-leg voltage source inverter (VSI) and photovoltaic (PV) installations in this paper. The PV VSI is designed to control active power at unity power factor (p.f) with additional improvement in the neutral current controller using the load generated neutral current as a direct reference. As, inherently, most of the three-phase four-wire LV distribution networks exhibit voltage unbalance characteristics due to divergent load connection types such as single- and threephase loads, the independent control over neutral current at the point of common coupling (PCC) becomes imperative especially for decentralized controllers. The improved performance of the neutral current controller both at customer's installation and at the distribution transformer (DT) terminal is investigated by implementing the designed PV-VSI with actual Australian (Energex) LV network model in PSCAD/EMTDC software environment. The performance of the designed four-leg VSI is compared with the traditional active neutral compensator with actual single phase customer loads. The results show that, with the proposed independent neutral current controller, improved neutral compensation can be achieved for unbalanced LV networks for whole day operations.
\end{abstract}

Index Terms - Voltage unbalance, four-leg inverter, unbalance loading, neutral current, actual LV network.

\section{INTRODUCTION}

Three-phase (3P) four-wire (4W) low voltage (LV) distribution networks are widely implemented in many countries particularly in south-east Asia pacific region and Australia to supply both single- and three-phase residential, commercial and industrial loads. The additional fourth-wire is connected to the grounding point of the delta/wye distribution transformer (DT) which is used as the return path for the single-phase load connections. Usually, the LV networks exhibit unbalanced characteristics due to unequal allocation of single-phase loads and nonlinear loads such as diode rectifiers, computers, adjustable speed drives, automatic office machines, and lighting ballasts [1]. Moreover, the rapid integration of hybrid renewable energy sources, such as photovoltaic units and battery energy storage systems are introducing excessive neutral current scenario in this kind of
LV networks. Excessive neutral current can cause overloading of the neutral conductors, mal-operation of sensitive electronic equipment, over-heating of the DT, raise electrical safety concerns because of increased ground voltage, and even cause a fire in some severe cases [2]. For instance, a survey in 1990 reported that $22.6 \%$ of computer sites in America were carrying more neutral current than the maximum full load phase-current capacity [3]. As a result, the independent active control over neutral currents are getting much attention in recent years [4] [5].

It is important to analyze the neutral compensation in a $\mathrm{LV}$ network using actual customer load and network characteristics to capture the realistic unbalanced loading conditions with renewable energy sources (RES), such as the photovoltaic (PV) units. Different neutral current compensation and phase balancing techniques have been proposed in literatures such as resizing the neutral conductor [6], installation of zigzag transformer (ZT) [1], delta-wye transformer [7], passive filter installation [8], and application of series [9] and shunt active power filters [10], hybrid power conditioners [11] etc. However, resizing the neutral conductor are costly and time consuming approach. Whereas, the passive harmonic filter introduces resonance problems within the network. It also produces interference with the communication link which is commonly installed close to the neutral line [12]. The ZT with unbalance voltage cases causes additional neutral current and thus it needs to be installed in close proximity to the customers, which makes the system bulkier. Alternatively, active neutral compensation can be utilized using the additional fourth leg from four leg VSI for better control flexibility and unbalanced load compensation [13]. The application of the four-leg VSI can be made more attractive for customers if it is incorporated with popular RES installations such as PV systems. Incorporation of a four-leg inverter with a PV source is proposed with multifunction operations such as active power regulation, reactive power compensation, and harmonic reduction and load neutral compensations in [14]. Faster fault recovery and lower reactive power requirements during network unbalances is proposed with unity pf four leg VSI in [15]; however, neutral compensation with actual customer loads is missing. 


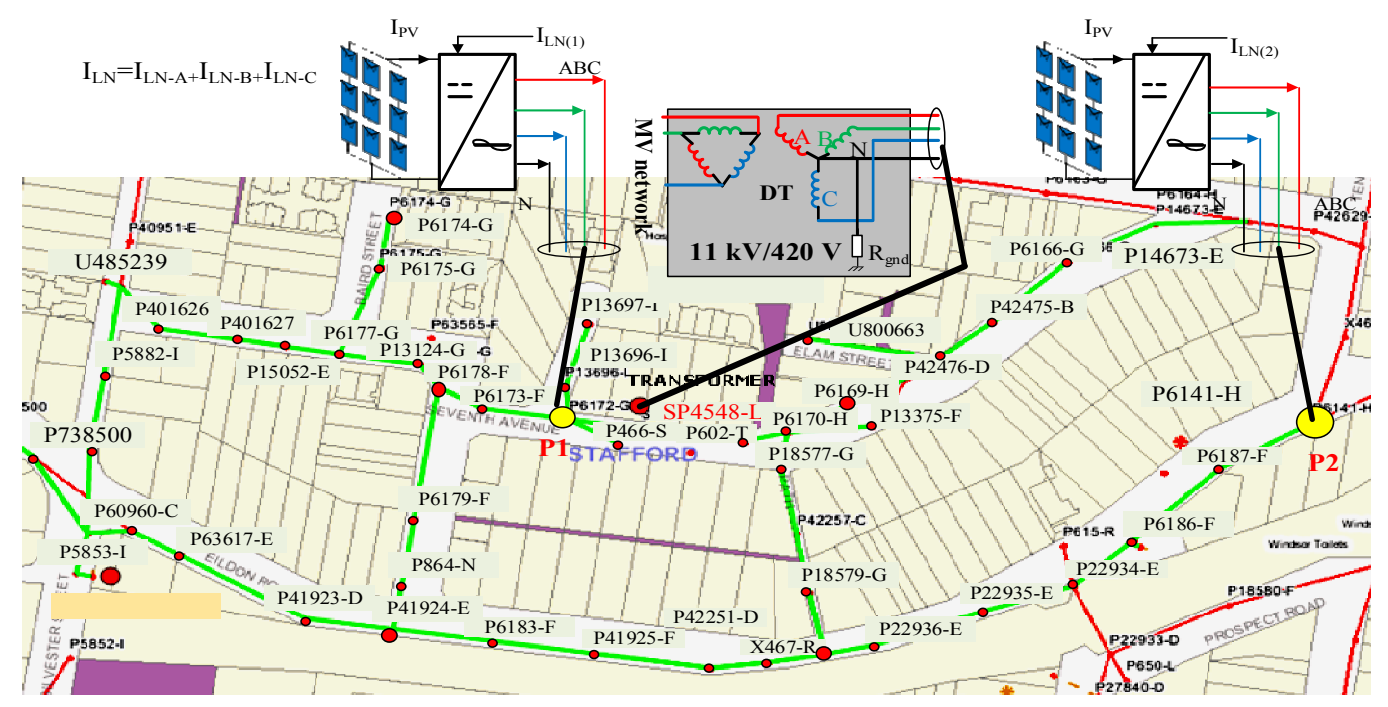

Figure 1. Designed four-leg VSI connection with the 3P-4W LV network.

Motivated by the aforementioned scopes, this paper presents the design of a four leg PV VSI with the aim of designing an independent improved neutral compensator integrated with PV installations utilizing a four leg VSI with the actual customer and LV network unbalance Characteristics. The unbalanced load generated neutral and zero sequence currents are proposed to utilize as direct references for the independent neutral and zero sequence controllers in this paper. The controller is designed to operate as decoupled from the active and reactive power controllers for whole day operation periods without any controller configuration changes. The results obtained from four leg VSI are compared with traditional active neutral compensators where the purpose of the neutral controller is to reduce PCC neutral current utilizing zero as a reference. The results show improved and stabilized neutral compensation performance from the designed PV-VSI system for whole day operation without any major transient phenomena.

The rest of this paper is organized as follows: Section II, the designed system configuration is described; in Section III, the unbalance loading effects and neutral compensation performance are analyzed with three case studies, and the paper concludes mentioning the future studies in Section IV.

\section{SYSTEM DESCRIPTION}

The designed PV system with four-leg VSI is connected in a three-phase (3P) four-wire (4W) Australian LV distribution network which is designed utilizing one year real customers' average load data from Newmarket zone substation area, Energex in Brisbane, Australia as shown in Fig. 1. As this paper mainly focuses on neutral compensation performance, the PV system is designed to operate at unity power factor, however, the four quadrant operations similar to three leg VSI can be found in our previously published paper in [16]. Traditionally, active neutral compensation with four-leg VSI is applied to negate the PCC point neutral current which works for active power filters but cannot reduce significant neutral current. As a result, the neutral connection from the distribution transformer (DT) compensates the remaining neutral current in the fourth wire in the LV network which causes overheating the transformer as well as the neutral wire. The additional fourth leg from the designed PV-VSI is utilized to compensate directly the load generated neutral and correspondingly zero sequence currents at the PCC which can significantly reduce overloading due to the excess load generated neutral currents. The relation between the zero sequence and neutral currents can be represented as:

$$
\begin{aligned}
& l_{f n}=-\Sigma l_{f(\sigma, b)} \text { in } a b c \text { frame } \\
& l_{f n}=-8 l_{f 0} \quad \text { in } d q 0 \text { frame }
\end{aligned}
$$

where, $I f a, I f b$ and $I f c$ are three-phase currents; $I_{n}$ is the neutral, and $\mathrm{If}_{0}$ is the zero sequence currents generated from the PV-VSI. Commonly used decoupled current controller is designed for active and reactive power controllers, and additional neutral and zero sequence current controllers are designed and implemented in this paper. The primary focus is given to the independent neutral current control at the PCC where the load generated neutral current is considered as the direct reference for the PV-VSI fourth leg controller as shown in Fig. 2, and results are compared with a traditional active neutral controller where the fourth leg VSI controller reference is considered as zero [17].The remaining components of the designed model consist of a LCL filter and a conventional PWM (pulse width modulation) switching mechanism, which is applied similarly as the three-leg VSI [18]. The dc-bus voltage is regulated at $700 \mathrm{~V}$ and the PI controllers are initially tuned using modulus optimum method and further fine-tuned to get an optimum response from the designed controller. All the parameters of the designed PVVSI system are given in the Appendix.

\section{CASE STUDIES AND DISCUSSIONS}

The considered LV network consists of both three- and single-phase customer connections and the distance between each customer is within 10-15 m (Urban area). Two testing points are considered for independent neutral compensation implementation with variable positive and zero sequence 


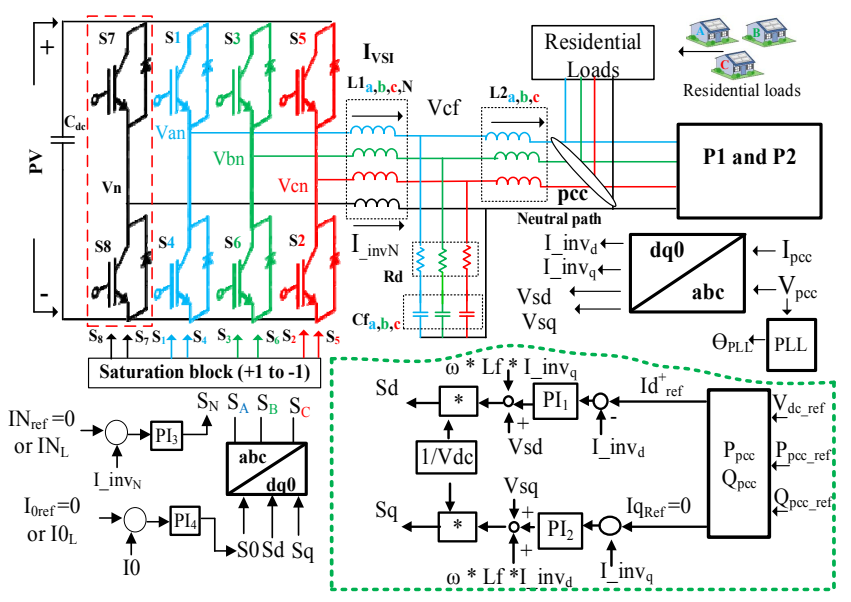

Figure 2. Detailed control diagram of four-leg PV-VSI.

$\mathrm{R} / \mathrm{X}$ ratios. The $\mathrm{LV}$ network $(11 \mathrm{kV} / 415 \mathrm{~V})$ is designed from the $33 / 11 \mathrm{kV}$ upstream network using the distribution transformer (DT) and transmission poles data from an inner northern residential suburb of Brisbane. The detailed of the LV network can be found in [19]. The LV network mainly consists of three-phase four-wire overhead distribution lines which are supplied from a $500 \mathrm{kVA}$ DT to 150 customers. One-year loading data of the individual customer is dynamically fed to the designed PSCAD LV network via calculating the resistive (R) and inductive (L) load values from active and reactive power consumptions. The details about the PV panels are presented in [18]. The parameters of the installed four-leg VSI at Griffith University's microgrid are used in this paper [20]. The purpose of the installed microgrid at Griffith University is to validate the feasibility of the four-quadrant PV VSI features with additional neutral current control in Australian LV networks. Therefore, the main focus of this section is to analyze the significant of the proposed independent neutral controller for full day operation utilizing the fixed capacity from the PV-VSI. Maximum \pm 25 $\mathrm{A}, \pm 15 \mathrm{~A}$, and $\pm 5 \mathrm{~A}$ current limit is considered for the active power, neutral and zero sequence current controllers. The designed VSI is implemented near the DT, and two customer points to analyze unbalance loading and LV network characteristics with the installed system. The case studies results show faster neutral compensation and stabilized whole day operation from the designed four leg PV-VSI without any control configuration change in the installed system.

\section{A. Load neutral generation effect on DT}

In this case study, neutral generation due to unbalance single phase loading effect on DT is presented. The active and reactive power customer load profiles and PV power generation are shown in Fig.3. It can be seen from Fig. 3, that the phase $\mathrm{C}$ is heavily loaded with 3 customers (each with $3 \mathrm{kw}$ and $0.55 \mathrm{kVA}$ rating) compared to other two phases with 2 customers' connection. This unbalanced loading is the main cause of significant neutral current generation at the PCC. The phase currents and load generated neutral and zero sequence currents are shown in Figs. 4 and
5. The main purpose of the application of the four leg VSI is to reduce

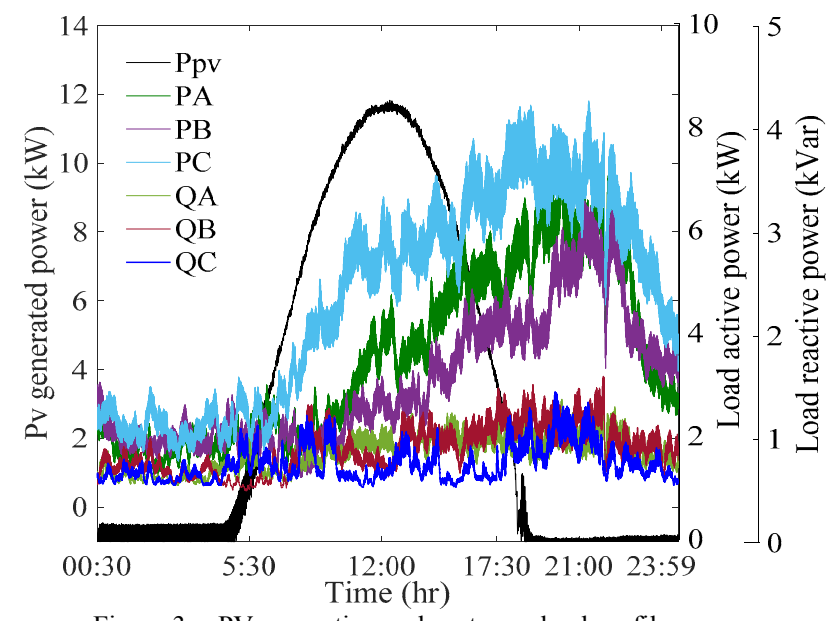

Figure 3. PV generation and customer load profiles.

this excess neutral current at the PCC to reduce the overloading effects on both the neutral conductor and the DT.

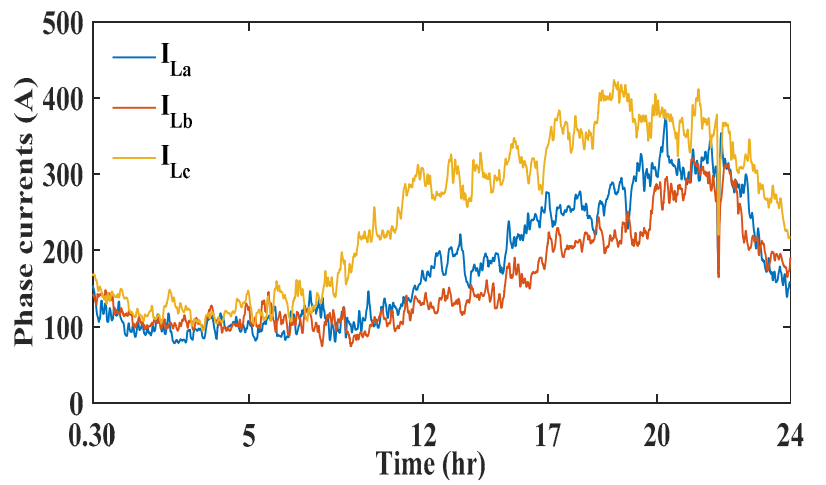

Figure 4. Phase currents at customer installation.

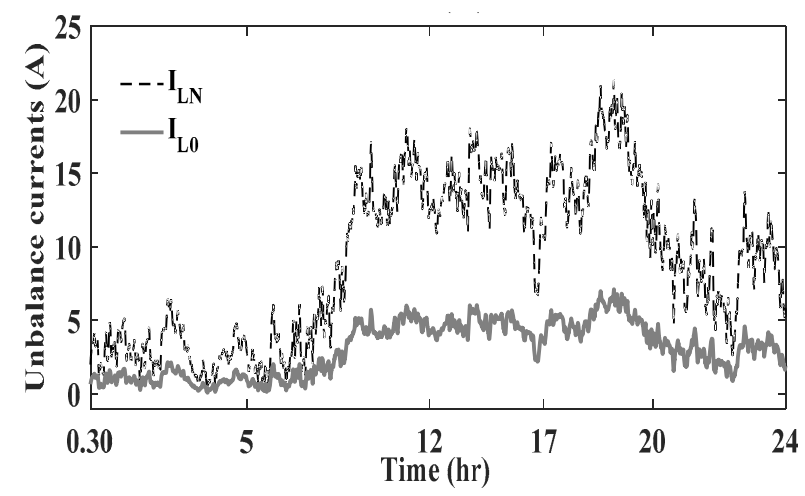

Figure 5. Load generated neutral and zero sequence currents.

The load connection is applied at the DT terminal point to evaluate the effect on DT. As can be seen from the Fig. 6, the DT is supplying around 158 A neutral current to compensate the load generated neutral for the LV network. The same customer connection is applied with four leg PV- VSI having traditional active compensator and the proposed compensator where the neutral reference is the direct input from the load generated neutral current. It can be seen from the Fig. 6, that, the proposed controller reduces the requirement of neutral current supply from the DT around $5 \mathrm{~A}$, whereas the 
traditional one reduces the neutral supply requirement only by $1 \mathrm{~A}$. It is evident that the proposed neutral compensator provides better compensation performance close to DT connection point. Application of the proposed PV-VSI is further discussed with independent neutral operation a customer connection points in the following case studies.

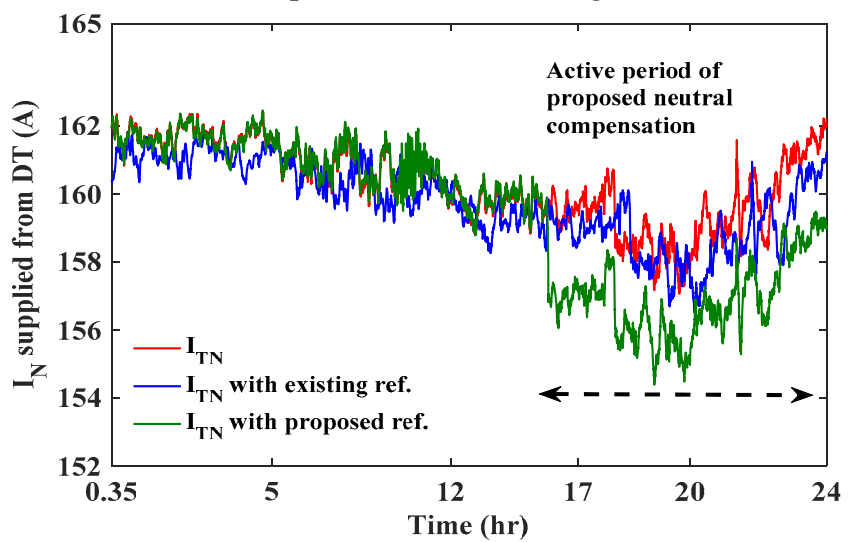

Figure 6. Neutral compensation effect on DT.

\section{B. Independent neutral current control performance}

In this case study, independent control over the neutral current is examined for whole day operation period. It is necessary to make sure that any change in neutral current should not affect the operation of active and reactive power controllers. For this analysis, initially the neutral and zero sequence current controller reference is set to zero similar as the traditional active compensator and after haft day operation, the reference is changed to the proposed method, i.e. load neutral current as a reference. The neutral current controller reference following operation with the modulation index for the PWM mechanism is presented in Figs 7 and 8.

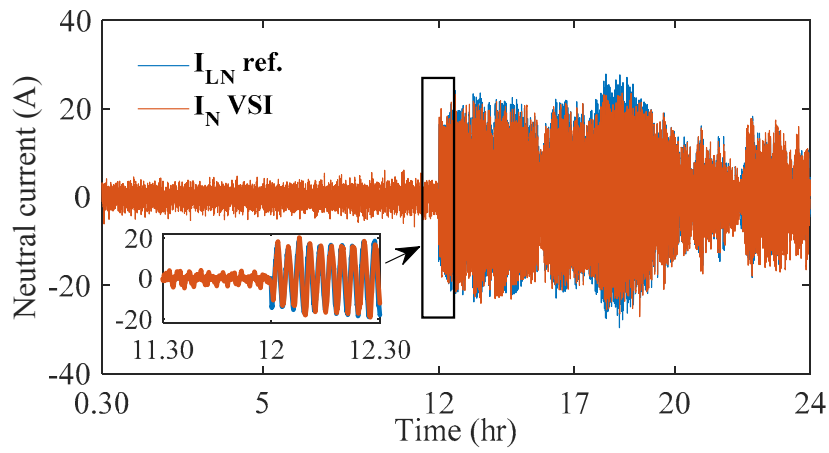

Figure 7. Independent neutral current control performance.

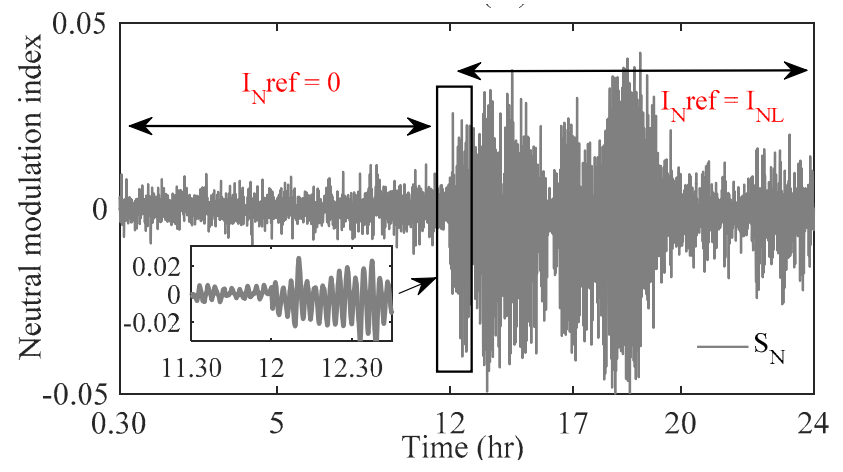

Figure 8. Neutral current controller modulation index.
It is evident from the results shown in Figs. 7 and 8, that the designed neutral controller can follow any neutral reference and can be operated as both traditional active compensator and proposed compensator without causing any major transient effects with the installed system. The overall stability of the installed system can be further clarified from the Fig. 9, where the phase modulation index remains within linear region despite the abrupt neutral controller reference changing operation, which verifies proper decoupled control operations of the neutral controller from active and reactive controllers.

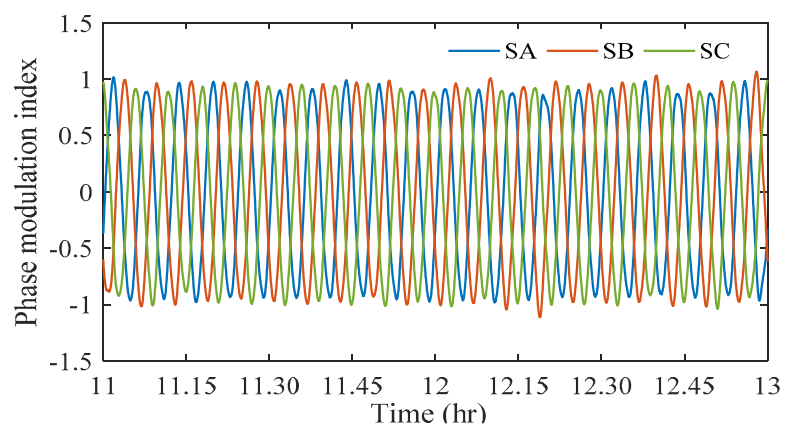

Figure 9. Phases modulation signals.

Fig. 10 shows the dc voltage controller performance where the dc voltage remains stable for the whole day operation period even with the neutral variations which signifies properly tuned controller characteristics and overall stability of the installed system. The neutral controller performance is evaluated at two customer points in the next case study.

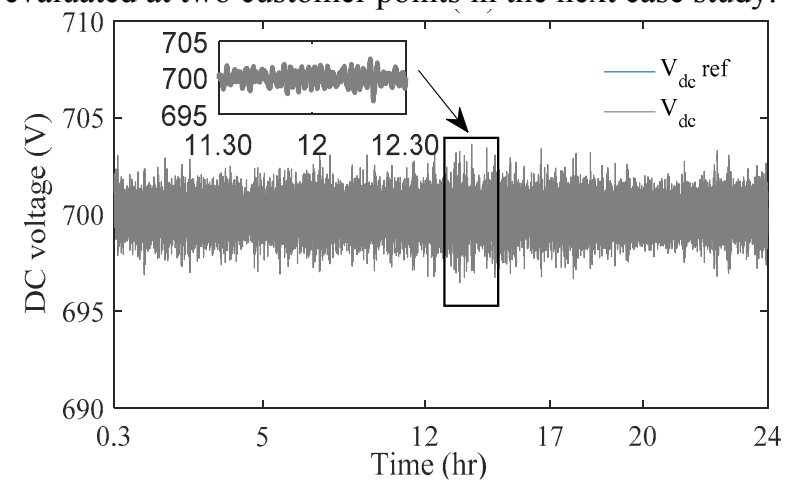

Figure 10. DC voltage regulator performance.

\section{Neutral compensation at customer installations}

In this case study, the application of the proposed neutral compensator is presented for two customer installations points. The details of the two customers network parameters are shown in Table 1 and graphically shown in Fig. 1. As can be seen from the above table, the customer close to the DT has very low $\mathrm{R} / \mathrm{X}$ parameters whereas the customer furthest to $\mathrm{DT}$ has positive sequence $\mathrm{R} / \mathrm{X}$ ratio over 1 and zero sequence $\mathrm{R} 0 / \mathrm{X} 0$ ratio nearly 0.75 . This variation in network parameter has effect on conrtolling active, reactive and the neutral currents and this case study analyses the effect of variable $\mathrm{R} 0 / \mathrm{X} 0$ ratios for neutral current control. 
TABLE I

CUSTOMER TESTING POINTS SPECIFICATIONS

\begin{tabular}{|c|c|c|c|}
\hline $\begin{array}{c}\text { Customer } \\
\text { point }\end{array}$ & $\begin{array}{c}\text { Distance } \\
\text { from DT }\end{array}$ & $\mathrm{R}_{+} / \mathrm{X}_{+}$ & $\mathrm{R}_{0} / \mathrm{X}_{0}$ \\
\hline $\mathrm{P} 1$ & $63.7 \mathrm{~m}$ & 0.92 & 0.55 \\
\hline $\mathrm{P} 2$ & $420 \mathrm{~m}$ & 1.50 & 0.75 \\
\hline
\end{tabular}

Initially, the customer loads are connected at P1 and the neutral compensation results presented in Fig. 11, where the case (a) represents traditional and case (b) proposed neutral compensation. It can be seen from Fig. 11 that even without the additional customer loads connection, the LV network exhibits neutral current around $27 \mathrm{~A}$ and with the addition of the loads this increases to maximum $42 \mathrm{~A}$ around 8-10 pm. The traditional neutral compensator can reduce around 2-3 A neutral current, whereas the proposed compensator can neutralized the load generated neutral current completely as shown in Fig 11.

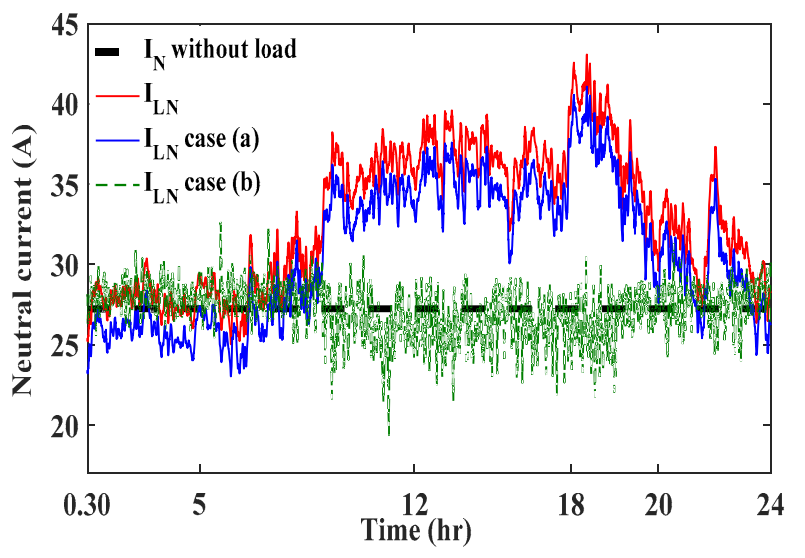

Figure 11. Neutral current compensation at testing point P1.

The same customer load is connected with the PV-VSI at the furthest point in the LV network, P2, and the performance comparison results for the neutral compensators are shown in Fig. 12. Here an additional case is included as a case (c) with half traditional and half proposed neutral compensator operation. Similar to the customer point 1, point 2 also exhibits neutral current around 7 A without any additional loads which represent inherent unbalance characteristics of the LV network. The results from the customer point P2 shows interesting characteristics. Load generated neutral current remains same around $15 \mathrm{~A}$, however, the case (a) compensates less neutral current than point P1. Similar lower neutral compensation performance can be observed from the designed controller such as around $8-10$ pm time, the neutral compensator provides less neural compensation. This is due higher $\mathrm{R} / \mathrm{X}$ ratios of point $\mathrm{P} 2$ than the point $\mathrm{P} 1$. Despite the lower compensation performance than the rated capacity from the proposed neutral compensator, it shows better performance than the traditional neutral compensators. It is evident from this case study that, even with variable network parameters, the proposed neutral compensator with load generated neutral current as a direct reference to the independent neutral controller provides improved neutral compensation with stabilized operation for whole day period.

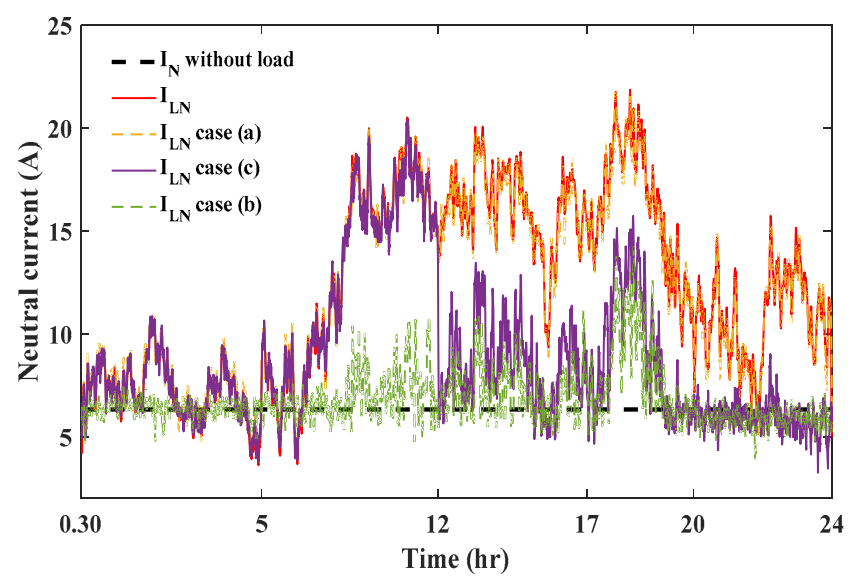

Figure 12. Neutral current compensation at testing point P2.

\section{CONCLUSION}

The designed four-leg VSI outstands the traditional active neutral compensator in the case of unbalance single phase loadings with an actual LV network. As, in practical cases, most of the three-phase four-wire LV networks show unbalanced characteristics due to divergent load connections and phases loading, application of the proposed four leg PVVSI can provide maximum capacity utilization with better neutral compensation at PCC from the installed system. The analysis results verify independent improved operation of the neutral current from the designed PV-VSI controller, and ensures properly decoupled operation from active and reactive controllers with stabilized characteristics for whole day operation without any controller setup configuration changes. Small scale experimental prototype set up is the future aim of this paper.

\section{ACKNOWLEDGEMENT}

The authors of this paper forward their sincerest thanks to ENERGEX, the electric power distribution company owned by the Queensland government, Australia, for providing the distribution network model for this research study. This research study is funded by the higher degree research scholarship program for international students from Griffith University, Australia.

\section{APPENDIX}

System description: PV module : 10 series and 2 parallel modules with 108 cells in series and 4 cells in parallel; DC link capacitor $=3000 \mu \mathrm{F}$, switching frequency $=3 \mathrm{kHz}$, simulation time step $=5 \mathrm{~ms}$, Inverter capacity $15 \mathrm{kVA}$; $\mathrm{DC}$ voltage regulator : $\mathrm{Kp}=8, \mathrm{Ti}=0.008$; active and reactive current controllers : $\mathrm{Kp}=8, \mathrm{Ti}=0.003$; neutral and zero sequence current controller: $\mathrm{Kp}=4, \mathrm{Ti}=0.05$; LCL filter : inverter side $\mathrm{L}=4 \mathrm{mH}, \mathrm{C}=10 \mu \mathrm{F}$, grid side $\mathrm{L}$ $=1 \mathrm{mH}$, damping resistor $=3 \mathrm{~m} \Omega$; Distribution grid: $240(\mathrm{~L}-\mathrm{N}) / 420(\mathrm{~L}-\mathrm{L})$ rms, $50 \mathrm{~Hz}, 150$ customers, $1.8 \mathrm{~km}$ total area, 2 loop network.

\section{REFERENCES}

[1]

H.-L. Jou, J.-C. Wu, K.-D. Wu, W.-J. Chiang, and Y.-H. Chen, "Analysis of zig-zag transformer applying in the three-phase fourwire distribution power system," IEEE Trans. Power Del., vol. 20, no. 2, pp. 1168-1173, 2005. 
[2] A. C. Liew, "Excessive neutral currents in three-phase fluorescent lighting circuits," IEEE Trans. Ind. Appl., vol. 25, no. 4. pp. 776782,1989

[3] T. M. Gruzs, "A survey of neutral currents in three-phase computer power systems," IEEE Trans. Ind. Appl., vol. 26, no. 4. pp. 719-725, 1990.

[4] L. Yunwei, D. M. Vilathgamuwa, and L. P. Chiang, "Microgrid power quality enhancement using a three-phase four-wire gridinterfacing compensator," IEEE Trans. Power Electron., vol. 19, no. 1, pp. 1707-1719, Nov./Dec. 2005.

[5] P. Lohia, M. K. Mishra, K. Karthikeyan, and K. Vasudevan, "A minimally switched control algorithm for three-phase four-leg VSI topology to compensate unbalanced and nonlinear load," Trans. Power Electron., vol. 23, no. 4, pp. 1935-1944, Jul. 2008.

[6] Electric Power Research Institute, Inc. Elevated Neutral-to-Earth Voltage, Urban Contact Voltage and Other Perceptibility Concerns for Humans and Animals [Online].

Available: http://strayvoltage.epri.com/results.asp.

[7] B. Singh, P. Jayaprakash, and D. P. Kothari, "Three-phase fourwire dstatcom with H-bridge VSC and star/delta transformer for power quality improvement," 2008 Annual IEEE India Conference, vol. 2. pp. 412-417, 2008.

[8] A. B. Nassif, W. Xu, and W. Freitas, "An Investigation on the selection of filter topologies for passive filter applications," IEEE Trans. Power Del., vol. 24, no. 3. pp. 1710-1718, 2009.

[9] O. Vodyakho and C. C. Mi, "Three-Level inverter-based shunt active power filter in three-phase three-wire and four-wire Systems," IEEE Trans. Ind. Electron., vol. 24, no. 5. pp. 1350$1363,2009$.

[10] P. Salmeron, and S. P. Litran, "Improvement of the electric power quality using series active and shunt passive filters," IEEE Trans.Power Del., vol. 25, no. 2, pp. 1058-1067, Apr. 2010.

[11] J. C. Wu, H. L. Jou, H. H. H. saio, and S. T. Xiao, "A new hybrid power conditioner for suppressing harmonics and neutral-line current in three-phase four-wire distribution power systems," IEEE Trans. Power Del., vol. 29, no. 4. pp. 1525-1532, 2014.

[12] K. W. Park, H. C. Seo, C. H. Kim, C. S. Jung, Y. P. Yoo, and Y. H. Lim, "Analysis of the neutral current for two-step-type poles in distribution lines," IEEE Trans. Power Del., vol. 24, no. 3. pp. 1483-1489, 2009.

[13] S. M. Ali and M. P. Kazmierkowski, "PWM voltage and current control of four-leg VSI," Industrial Electronics, 1998. Proceedings. ISIE '98. IEEE International Symposium on, vol. 1. pp. 196-201 vol.1, 1998.

[14] M. Singh, V. Khadkikar, A. Chandra, and R. K. Varma, "Grid interconnection of renewable energy sources at the distribution level with power-quality improvement features," IEEE Trans. Power Del., vol. 26, no. 1. pp. 307-315, 2011.

[15] F. H. M. Rafi, M. J. Hossain, M.S. Rahman, and J. Lu, "Impact of controlling zero sequence current in a three-phase four-wire LV network with PV units," accepted in the Power \& Energy Society General Meeting, 2016 IEEE. pp. 1-5, 2016.

[16] F. H. M. Rafi, M. J. Hossain, D. Leskarac, and J. Lu, "Reactive power management of a AC/DC microgrid system using a smart PV inverter," IEEE Power \& Energy Society General Meeting, 2015.

[17] X. Wang, F. Zhuo, J. Li, L. Wang, and S. Ni, "Modeling and control of dual-stage high-power multifunctional PV system in dq-o-Coordinate," IEEE Transactions on Industrial Electronics, vol. 60(4), pp. 1556-1570, 2013.

[18] F. H. M. Rafi, M. J. Hossain, and J. Lu, "Hierarchical controls selection based on PV penetrations for voltage rise mitigation in a LV distribution network," International Journal of Electrical Power \& Energy Systems, vol. 81, pp. 123-139, 2016.

[19] F. H. M. Rafi, M. J. Hossain, and J. Lu, "Design of a single stage transformerless VSI in a smart microgrid for PV-STATCOM/ESS operations," In Proceedings of Australasian Universities Power Engineering Conference, 2014.

[20] M. S. Rahman, M. J. Hossain, and J. Lu, "Coordinated control of three-phase ac and dc type EV-ESSs for efficient hybrid microgrid operations," Energy Conversion and Management, vol. 122, pp. 488-503, 2016. 